\section{A Comparison of Disease Severity and Outcomes in COVID-19 Cases Taking Angiotensin- Converting Enzyme Inhibitors/Angiotensin Receptor Blockers Versus Other Antihypertensive Drugs}

Muhammad Abdullah Sr. ${ }^{1}$, Khurshid Khan ${ }^{1}$, Munaza Javed ${ }^{2}$, Javeid Iqbal ${ }^{3}$, Khalid Waheed ${ }^{4}$, Muhammad Naeem Akhtar ${ }^{4}$, Aijaz Zeeshan Khan Chachar ${ }^{5}$

1. Internal Medicine and Endocrinology, Fatima Memorial Hospital College of Medicine and Dentistry, Lahore, PAK 2. Internal Medicine, University College of Medicine, the University of Lahore Teaching Hospital, Lahore, PAK 3. Medicine, Fatima Memorial Hospital College of Medicine and Dentistry, Lahore, PAK 4. Pulmonology, Lahore General Hospital, Lahore, PAK 5. Internal Medicine, Fatima Memorial Hospital College of Medicine and Dentistry, Lahore, PAK

Corresponding author: Muhammad Abdullah Sr., mad_ghuffi@hotmail.com

\section{Abstract}

\section{Objective}

In this study, we aimed to compare the severity and outcomes in hypertensive patients presenting with coronavirus disease 2019 (COVID-19) who were taking angiotensin-converting enzyme inhibitors (ACEIs)/angiotensin receptor blockers (ARBs) and those who were on other antihypertensive drugs.

\section{Methods}

This retrospective cohort study involved 182 hypertensive patients who presented with COVID-19 infection. The study population comprised 91 patients who were taking ACEIs/ARBs (group A) and 91 patients who were taking other antihypertensive drugs such as $\beta$-blockers (BBs), calcium channel blockers (CCBs), or thiazides (group B). All patients were provided the same type of treatment for the management of COVID19. We recorded the data related to demographic and anthropometric variables as well as clinical symptoms during the treatment period. Disease severity and hospital mortality were the primary study endpoints.

\section{Results}

There was no significant difference in COVID-19-related outcomes between the groups except for the severity of lung infiltration on chest X-rays. There were 37 (41.1\%) patients having $>50 \%$ lung infiltration in group A and 53 (58.2\%) in group B (p-value: 0.02). Severe disease was diagnosed in 37 (40.7\%) patients in group A compared to 39 (42.7\%) patients in group B (p-value: 0.76 ). In-hospital mortality was noted in 17 (18.7\%) patients in group A and 22 (24.2\%) patients in group B (p-value: 0.36$)$.

Review began $12 / 31 / 2020$ Review ended 01/13/2021 Published 01/18/2021

๑) Copyright 2021

Abdullah et al. This is an open access article distributed under the terms of the Creative Commons Attribution License CC-BY 4.0., which permits unrestricted use, distribution, and reproduction in any medium, provided the original author and source are credited.

\section{Conclusion}

Based on our results, we did not find any significant association between the use of ACEIs/ARBs and either the severity of COVID-19 infection necessitating admission to ICU or in-hospital mortality.

Categories: Internal Medicine, Infectious Disease

Keywords: covid-19, hypertension, aceis, arbs

\section{Introduction}

Coronavirus disease 2019 (COVID-19) was first reported in late 2019 from Wuhan, China, and it quickly spread all over the world within months, becoming a global pandemic. The disease is associated with severe respiratory compromise leading to high mortality rates, usually due to multi-organ failure [1]. Researchers have identified the risk factors that can potentially lead to increased susceptibility and severity of the disease and thereby worsen the outcomes in patients. Many recent studies conducted on COVID-19 patients have focused on comorbidities like cardiovascular disease (CVD), diabetes, and hypertension [2,3]. A metaanalysis of eight studies on the risk factors in COVID-19-infected patients has reported hypertension to be the most common comorbidity (17.1\%), followed by CVD (16.4\%) and diabetes (9.7\%). The mortality rate in hypertensive patients was $6.0 \%$, compared to $2.3 \%$ in patients without any of the above-mentioned morbidities [4].

The majority of hypertensive patients are prescribed angiotensin-converting enzyme inhibitors (ACEIs)/angiotensin receptor blockers (ARBs). Researches have reported that the use of these drugs causes 
the upregulation of ACE2 receptors (the main receptor of cell entry for COVID-19) and hence may increase vulnerability to COVID-19 infection and its severity $[5,6]$. So, in view of these findings, many researchers have raised concerns about the use of ACEIs and ARBs for the management of hypertension during the COVID-19 pandemic. However, data from some studies have reported no association between COVID-19 risk or its severity and patients taking these drugs [7,8]. This has led experts to conclude that there is insufficient data to support the discontinuation of ARBs and ACEIs during the COVID-19 pandemic, and they have called for more researches on the subject to reach more definitive conclusions. In light of this, we undertook the current study to compare the disease severity and outcomes in COVID-19 patients taking ACEIs/ARBs with those taking other antihypertensive drugs.

\section{Materials And Methods}

This retrospective cohort study involved 182 hypertensive patients who presented with COVID-19 infection to the department of medicine in three tertiary care hospitals in Lahore City, Pakistan. Hypertensive patients who have been under treatment for the condition for $>6$ months were included. Patients were divided into two groups: group A consisted of patients taking ACEIs/ARBs for their hypertension, and group B comprised hypertensive patients on medications other than ACEIs/ARBs. Patients with previous evidence of lung disease, e.g., those with asthma, chronic obstructive pulmonary disease (COPD), interstitial lung disease (ILD), or those having chronic renal or liver disease were excluded from the study. The data were collected from patients admitted within the last six months.

The study population comprised 91 patients who were taking ACEIs/ARBs (group A) and 91 patients who were taking other antihypertensive drugs such as $\beta$-blockers (BBs), calcium channel blockers (CCBs), or thiazides group A.

The data were retrieved retrospectively from medical records at the hospitals. Demographic and anthropometric variables, clinical symptoms during the treatment period, overall disease severity, and hospital mortality were recorded. Disease severity was determined according to the Pakistan guidelines on COVID-19, which were published in June 2020. Patients were considered to have severe disease if fever and cough were associated with the following conditions: respiratory rate of $>30$ breaths per minute, severe respiratory distress, oxygen saturation $\left(\mathrm{SpO}_{2}\right)$ of $\leqslant 90 \%$ on room air, and chest X-rays showing $>50 \%$ lung infiltration. The treatment regimen consisted of tocilizumab (as per indication), azithromycin, methylprednisolone, and enoxaparin for all patients.

Data analysis was conducted using the SPSS Statistics software version 25.0 (IBM, Armonk, NY). Independent samples t-test and chi-squared test were used for comparison of quantitative variables and qualitative variables respectively. A p-value of $\leqslant 0.05$ was considered statistically significant.

\section{Results}

There was no significant difference in terms of mean age, the duration of hypertension, and the presence of diabetes mellitus between the groups. There were 67 (73.6\%) male patients in group A and 52 (57.1\%) in group B (p-value: 0.02). There were more patients having ischemic heart disease (IHD) in group A: 30 (33\%) versus 11 (12.1\%) in group B (p-value: 0.001) (Table 1).

There was no significant difference in COVID-19-related outcomes between the groups except for the severity of lung infiltration on chest X-rays. There were 37 (41.1\%) patients having $>50 \%$ lung infiltration in group A and 53 (58.2\%) in group B (p-value: 0.02). The mean length of hospital stay was $7.26 \pm 4.26$ days in group A and $7.53 \pm 4.64$ days in group B (p-value: 0.68). Severe disease was diagnosed in 37 (40.7\%) patients in group A and 39 (42.7\%) patients in group B (p-value: 0.76); the difference was not statistically significant. In-hospital mortality was noted in 17 (18.7\%) patients in group A and 22 (24.2\%) patients in group B (pvalue: 0.36 ) (Table 2).

We found a strong association between the duration of hypertension among patients and in-hospital mortality rates. The duration of hypertension was $12.89 \pm 9.26$ years in patients who died versus $9.48 \pm 8.32$ years in those who survived, with a regression coefficient value of 1.04 and p-value of 0.03 (Table 3). 


\section{Cureus}

\begin{tabular}{|c|c|c|c|}
\hline Variables & Group A & Group B & P-value \\
\hline Age in years, mean $\pm S D$ & $59.04 \pm 13.34$ & $61.71 \pm 10.27$ & 0.13 \\
\hline \multicolumn{4}{|l|}{ Gender } \\
\hline Male, $n(\%)$ & $67(73.6 \%)$ & $52(57.1 \%)$ & \multirow{2}{*}{0.02} \\
\hline Female, $n(\%)$ & $24(26.4 \%)$ & $39(42.9 \%)$ & \\
\hline Duration of hypertension (years), mean $\pm S D$ & $9.82 \pm 9.52$ & $10.60 \pm 7.64$ & 0.54 \\
\hline Diabetes mellitus, $\mathrm{n}(\%)$ & $53(58.2 \%)$ & $48(52.7 \%)$ & 0.45 \\
\hline IHD, n (\%) & $30(33 \%)$ & $11(12.1 \%)$ & 0.001 \\
\hline
\end{tabular}

TABLE 1: Comparison of baseline variables between the groups

SD: standard deviation; IHD: ischemic heart disease

\begin{tabular}{|c|c|c|c|}
\hline Variables & Group A & Group B & P-value \\
\hline Duration of COVID-19 infection (days), mean \pm SD & $5.26 \pm 2.10$ & $5.60 \pm 2.66$ & 0.34 \\
\hline Oxygen saturation (\%), mean $\pm S D$ & $84.4 \pm 14.44$ & $83.13 \pm 14.10$ & 0.54 \\
\hline Respiratory rate (breaths per minute), mean \pm SD & $30.27 \pm 13.11$ & $31.28 \pm 10.05$ & 0.56 \\
\hline Systolic blood pressure $(\mathrm{mmHg})$, mean $\pm \mathrm{SD}$ & $128.03 \pm 22.64$ & $125.71 \pm 21.43$ & 0.47 \\
\hline >50\% lung infiltration on CXR, n (\%) & $37(41.1 \%)$ & $53(58.2 \%)$ & 0.02 \\
\hline Overall disease severity, $\mathrm{n}(\%)$ & $37(40.7 \%)$ & 39 (42.9\%) & 0.76 \\
\hline ICU admission, $\mathrm{n}(\%)$ & $28(30.8 \%)$ & $38(41.8 \%)$ & 0.12 \\
\hline Hospital stay (days), mean $\pm S D$ & $7.26 \pm 4.26$ & $7.53 \pm 4.64$ & 0.68 \\
\hline In-hospital mortality, n (\%) & $17(18.7 \%)$ & $22(24.2 \%)$ & 0.36 \\
\hline
\end{tabular}

\section{TABLE 2: Comparison of COVID-19-related variables between the groups}

COVID-19: coronavirus disease 2019; SD: standard deviation; CXR: chest X-ray; ICU: intensive care unit

\begin{tabular}{|c|c|c|c|c|}
\hline & \multicolumn{2}{|c|}{ In-hospital mortality } & \multirow{2}{*}{ Regression coefficient ( $\beta$ ) } & \multirow{2}{*}{ P-value } \\
\hline & Yes & No & & \\
\hline Duration of HTN (years), mean \pm SD & $12.89 \pm 9.26$ & $9.48 \pm 8.32$ & $1.04(1.0-1.08)$ & 0.03 \\
\hline
\end{tabular}

\section{TABLE 3: Association between the duration of hypertension and in-hospital mortality}

HTN: hypertension; SD: standard deviation

\section{Discussion}

The present study did not find any significant difference between patients taking ACEIs/ARBs and those taking other antihypertensive drugs in terms of disease severity and outcomes. The hypothesis that the use of ACEIs/ARBs can increase the chances of COVID-19 infection and its severity emerged from studies conducted on animals $[9,10]$. These studies reported that the ACE2 enzyme, a protein located on cell membranes, is used by severe acute respiratory syndrome coronavirus 2 (SARS-CoV-2) as a receptor to enter into the cells. However, studies have not reported any clear association between the upregulation of 
ACE2 and susceptibility and severity of COVID-19 infection [11-13]. The ACE2 is widely spread all over the body including alveoli, which is the main point of entry for SARS-CoV-2.

A recent review by Vaduganathan et al. analyzed the association between the use of ACEIs and COVID-19 and reported that there is insufficient data to determine whether effects on ACE2 receptors in humans caused by the use of ACEIs are similar to those found in animal studies. The results of the trials on the use of the renin-angiotensin-aldosterone system (RAAS) to determine whether the use of drugs such as valsartan or recombinant human ACE2 is beneficial in reducing the susceptibility and severity of symptoms have not been published yet. Moreover, the sudden withdrawal of ACEIs/ARBs, especially in high-risk patients such as those having heart failure or myocardial infarction, can cause hemodynamic instability or adverse health results. Hence, the authors recommended continuing the use of ACEIs/ARBs until sufficient evidence is available to justify the discontinuation of the use of ACEIs/ARBs in COVID-19 patients [14].

A study by Fosbøl et al. compared the outcomes in hypertensive patients with COVID-19 taking ACEIs/ARBs with those taking other antihypertensive drugs; the authors reported a mortality rate of $20.2 \%$ in patients taking ACEIs/ARBs and $8.3 \%$ in patients taking other drugs, while severe disease was diagnosed in $22.6 \%$ of patients taking ACEIs/ARBs compared to $10.4 \%$ of patients taking other drugs. However, after adjusting for age and gender, the mortality rate was found to be $9.4 \%$ in patients taking ACEIs/ARBs versus $9.7 \%$ in patients taking other drugs. Our findings contrast with these results and showed an in-hospital mortality of $18.7 \%$ in patients in group A and $24.2 \%$ in patients in group B (p-value: 0.36 ). Regarding disease severity, the authors concluded that the prior administration of ACEIs/ARBs did not increase the severity and mortality in hypertensive patients presenting with COVID-19 [15], which is highly comparable with our findings as our study also yielded no statistically significant difference in disease severity between group A (40.7\%) and group B (42.7\%) (p-value: 0.76).

Mehra et al. have also reported that the use of ACEIs had no association with an increase in COVID-19related mortality [16], and their results are consistent with our study. A recent study by Hippisley-Cox et al. has reported that the use of ACEIs/ARBs significantly reduces the risk of acquiring COVID-19. They also reported that the use of ACEIs/ARBs did not increase the risk of admission to ICU [17], which aligns with our results, which also revealed that the prior use of ACEIs/ARBs did not escalate the risk of ICU transfer.

A study by Yan et al. has reported that the use of ACEIs can lead to a protective effect in COVID-19 patients. The authors reported a mortality rate of $19.4 \%$ in patients taking no antihypertensive drugs, $13.9 \%$ in those taking thiazides, $8.3 \%$ in those taking BBs, $5.8 \%$ in those taking CCBs, $8.3 \%$ in those taking ARBs, and $2.8 \%$ in those taking ACEIs. Severe disease was diagnosed in $14.8 \%$ of patients taking no drugs, $62.7 \%$ of those taking CCBs, $13.6 \%$ of those on BBs, $18.3 \%$ of those on ARBs, and only $5.3 \%$ of those taking ACEIs [18].

\section{Conclusions}

The present study did not find any significant association between the use of ACEIs/ARBs and either the severity of COVID-19 infection necessitating admission to ICU or in-hospital mortality. Hence, our results discourage discontinuing the use of ACEIs/ARBs in hypertensive patients during the ongoing COVID-19 pandemic.

\section{Additional Information \\ Disclosures}

Human subjects: Consent was obtained or waived by all participants in this study. Institutional Review Board, Fatima Memorial Hospital College of Medicine and Dentistry issued approval FMH-09-2020-IRB-786M. This study was approved by the Institutional Review Board at the Fatima Memorial Hospital College of Medicine and Dentistry. Animal subjects: All authors have confirmed that this study did not involve animal subjects or tissue. Conflicts of interest: In compliance with the ICMJE uniform disclosure form, all authors declare the following: Payment/services info: All authors have declared that no financial support was received from any organization for the submitted work. Financial relationships: All authors have declared that they have no financial relationships at present or within the previous three years with any organizations that might have an interest in the submitted work. Other relationships: All authors have declared that there are no other relationships or activities that could appear to have influenced the submitted work.

\section{References}

1. Goyal P, Choi JJ, Pinheiro LC, et al.: Clinical characteristics of Covid-19 in New York City . N Engl J Med. 2020, 382:2372-4. 10.1056/NEJMc2010419

2. Fang L, Karakiulakis G, Roth M: Are patients with hypertension and diabetes mellitus at increased risk for COVID-19 infection?. Lancet Respir Med. 2020, 8:e21. 10.1016/S2213-2600(20)30116-8

3. Sommerstein R, Kochen MM, Messerli FH, Gräni C: Coronavirus disease 2019 (COVID-19): do angiotensinconverting enzyme inhibitors/angiotensin receptor blockers have a biphasic effect? J Am Heart Assoc. 2020, 9:e016509. 10.1161/JAHA.120.016509

4. Chopra HK, Kasliwal RR, Muruganathan A, Wali M, Ram CVS: COVID-19, hypertension, and cardiovascular 
disease. J Diabetol. 2020, 11:57-64. 10.4103/JOD.JOD 3020

5. Hoffmann M, Kleine-Weber H, Schroeder S, et al.: SARS-CoV-2 cell entry depends on ACE2 and TMPRSS2 and is blocked by a clinically proven protease inhibitor. Cell. 2020, 181:271-80. 10.1016/j.cell.2020.02.052

6. Li W, Moore MJ, Vasilieva N, et al.: Angiotensin-converting enzyme 2 is a functional receptor for the SARS coronavirus. Nature. 2003, 426:450-4. 10.1038/nature02145

7. Li J, Wang X, Chen J, Zhang H, Deng A: Association of renin-angiotensin system inhibitors with severity or risk of death in patients with hypertension hospitalized for coronavirus disease 2019 (COVID-19) infection in Wuhan, China. JAMA Cardiol. 2020, 5:825-30. 10.1001/jamacardio.2020.1624

8. Mancia G, Rea F, Ludergnani M, Apolone G, Corrao G: Renin-angiotensin-aldosterone system blockers and the risk of Covid-19. N Engl J Med. 2020, 382:2431-40. 10.1056/NEJMoa2006923

9. Diaz JH: Hypothesis: angiotensin-converting enzyme inhibitors and angiotensin receptor blockers may increase the risk of severe COVID-19. J Travel Med. 2020, 27:taaa041. 10.1093/itm/taaa041

10. Esler M, Esler D: Can angiotensin receptor-blocking drugs perhaps be harmful in the COVID-19 pandemic? . J Hypertens. 2020, 38:781-2. 10.1097/HJH.0000000000002450

11. Ferrario CM, Jessup J, Chappell MC, et al.: Effect of angiotensin-converting enzyme inhibition and angiotensin II receptor blockers on cardiac angiotensin-converting enzyme 2. Circulation. 2005, 111:260510. 10.1161/CIRCULATIONAHA.104.510461

12. Hamming I, Timens W, Bulthuis ML, Lely AT, Navis G, van Goor H: Tissue distribution of ACE2 protein, the functional receptor for SARS coronavirus. A first step in understanding SARS pathogenesis. J Pathol. 2004, 203:631-7. 10.1002/path.1570

13. Burchill LJ, Velkoska E, Dean RG, Griggs K, Patel SK, Burrell LM: Combination renin-angiotensin system blockade and angiotensin-converting enzyme 2 in experimental myocardial infarction: implications for future therapeutic directions. Clin Sci (Lond). 2012, 123:649-58. 10.1042/CS20120162

14. Vaduganathan M, Vardeny O, Michel T, McMurray JJV, Pfeffer MA, Solomon SD: Renin-angiotensinaldosterone system inhibitors in patients with Covid-19. N Engl J Med. 2020, 382:1653-9. 10.1056/NEJMsr2005760

15. Fosbøl EL, Butt JH, Østergaard L, et al.: Association of angiotensin-converting enzyme inhibitor or angiotensin receptor blocker use with COVID-19 diagnosis and mortality. JAMA. 2020, 324:168-77. 10.1001/jama.2020.11301

16. Mehra MR, Desai SS, Kuy S, Henry TD, Patel AN: Cardiovascular disease, drug therapy, and mortality in Covid-19. N Engl J Med. 2020, 382:e102. 10.1056/NEJMoa2007621

17. Hippisley-Cox J, Young D, Coupland C, et al.: Risk of severe COVID-19 disease with ACE inhibitors and angiotensin receptor blockers: cohort study including 8.3 million people. Heart. 2020, 106:1503-11. 10.1136/heartinl-2020-317393

18. Yan F, Huang F, Xu J, et al.: Antihypertensive drugs are associated with reduced fatal outcomes and improved clinical characteristics in elderly COVID-19 patients. Cell Discov. 2020, 6:77. 10.1038/s41421-02000221-6 